\title{
Prolonged dual antiplatelet therapy: a potential mitigator of the adverse effects of local haemodynamic shear stress in high-risk coronary regions?
}

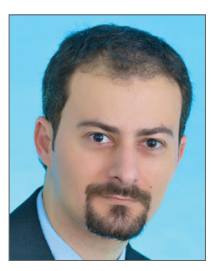

Michail I. Papafaklis ${ }^{1,2 *}$, MD, PhD, FESC; Michail C. Mavrogiannis ${ }^{1}, \mathrm{MD}$; Lampros K. Michalis ${ }^{1,2}$, MD, MRCP, FESC

1. Michailideion Cardiac Center, Medical School, University of Ioannina, Ioannina, Greece; 2. Second Department of Cardiology, University Hospital of Ioannina, Ioannina, Greece
Dual antiplatelet therapy (DAPT) is essential for protection against stent thrombosis after percutaneous coronary intervention (PCI). Additionally, the benefits of antiplatelet therapy potentially extend to the entire coronary vasculature preventing atherothrombotic events due to plaque rupture. Since the observed benefits come at the cost of increased bleeding risk, deciding on the duration of DAPT (i.e., the time for ceasing DAPT) is critical for longterm patient outcomes. The recommended duration of DAPT in the current guidelines ranges from one up to 12 months according to two standardised criteria: stent type (bare metal stents and generation of drug-eluting platforms) and clinical presentation (acute coronary syndrome vs. stable angina $)^{1}$.

Recent randomised clinical trials have shown benefit in ischaemic events with long-duration ( $>1$ year) DAPT, which is in large part due to a reduction in events unrelated to coronary stents; more than $50 \%$ of the reduction in myocardial infarctions observed with 30-month DAPT (vs. 12-month regimen) was not related to stent thrombosis in the DAPT trial ${ }^{2}$, and recurrent myocardial infarction was the most frequent ischaemic event (5.2\%), with definite stent thrombosis being rare $(0.7 \%)$, i.e., only a small portion of ischaemic events, among patients with stents randomised to placebo in the PEGASUS-TIMI 54 trial $^{3}$. With a consistent finding of higher bleeding rates in the prolonged DAPT arms $s^{2,3}$, identifying those patients with increased systemic thrombotic risk (and acceptable bleeding risk) who would benefit most from prolonged DAPT is of the utmost importance. Therefore, an individualised approach has been proposed, taking into consideration multiple patient characteristics for systemic thrombosis, and factors related to the device and the procedure in the case of stent thrombosis ${ }^{4}$.

In this context of determining the thrombotic risk, Costa et $\mathrm{al}^{5}$ report their post hoc analysis from the Prolonging Dual Antiplatelet Treatment After Grading Stent-Induced Intimal Hyperplasia (PRODIGY) trial which randomised patients after PCI (balanced Article, see page 1222

mixture of first- and second-generation drug-eluting stents and bare metal stents) to either 24- or six-month DAPT with aspirin and clopidogrel. The post hoc analysis showed a signal of benefit in two-year clinical outcomes from prolonged DAPT in cases with angiographic ( $\geq 30 \%$ ) luminal narrowing in the left main (LM) and/or proximal left anterior descending ( $\mathrm{pLAD}$ ) coronary arteries. Regarding stent-related events, there was a $50 \%$ reduction in definite, probable or possible stent thrombosis in patients with (2.8\% for 24 -month vs. $5.6 \%$ for six-month DAPT; $\mathrm{p}=0.02$ ) but not in those without $\mathrm{LM} / \mathrm{pLAD}$ narrowing irrespective of stenting performed in the $\mathrm{LM} / \mathrm{pLAD}$. Of interest, an absolute decrease in the composite endpoint of cardiovascular death or myocardial infarction was observed after prolonged DAPT in patients with $\mathrm{LM} / \mathrm{pLAD}$ narrowing $(6.6 \%$ for 24 -month vs. $8.3 \%$ for 
six-month DAPT; $\mathrm{p}=0.21$ ), whereas there was an absolute increase in the group without $\mathrm{LM} / \mathrm{pLAD}$ narrowing $(6.2 \%$ for $24-\mathrm{month}$ vs. $4 \%$ for six-month DAPT; $\mathrm{p}=0.15$ ). These findings combined yielded a trend towards interaction between DAPT duration and the presence of $\mathrm{LM} / \mathrm{pLAD}$ lumen narrowing $(\mathrm{p}=0.056$ for interaction). Although after adjustment for baseline clinical/angiographic imbalances the rate of major adverse cardiac events did not differ significantly between patients with and without LM/ pLAD lumen narrowing, and crude differences may be in part due to more extensive disease and more complex interventional treatment (larger metal burden) in the group with LM/pLAD narrowing, it is intriguing to speculate that the observed benefit may also be related to the favourable effect of prolonged DAPT on the "bystander atherosclerotic disease".

The study by Costa et $\mathrm{al}^{5}$ highlights that the location of the disease contributes to the conferred risk of future adverse events in the coronary tree. Local factors, in particular haemodynamic shear stress (SS), are responsible for the site-specific nature of atherosclerosis at both early and advanced stages of the disease ${ }^{6}$. Low local SS is known to have a great pro-atherogenic and pro-inflammatory effect leading to plaque development/progression in native regions and augmented intimal hyperplasia in stented areas? Recent studies in humans have also demonstrated that low SS is associated with higher-risk plaque characteristics (larger lipid burden, thinner fibrous caps, larger density of macrophages), and, overall, with a higher prevalence of thin-cap atheromas ${ }^{8}$.

The proximal regions of the left coronary tree - in part due to the larger vessel calibre contributing to relatively slower blood velocity - and the outer waist of coronary bifurcations (such as the left main bifurcation), where flow division and disturbance occur, are particularly subject to low local $\mathrm{SS}^{9}$. Atherosclerosis occurs more frequently in these regions, while atherosclerotic plaques exhibit more positive remodelling and a higher percentage of large necrotic cores, with an increased clustering of thin-cap atheromas in the proximal areas of the coronary tree compared to the distal ones ${ }^{10-12}$, as the authors also point out in their discussion ${ }^{5}$. Therefore, the atherosclerotic lesions in the $\mathrm{LM} / \mathrm{pLAD}$ culminate more frequently in a vulnerable plaque phenotype, and, under an ongoing stimulus of low local SS, may become particularly unstable and lead to future acute coronary syndromes ${ }^{13,14}$. A $\sim 5$-fold higher incidence of cardiac events has been demonstrated in lumen narrowings not significant by angiography but featuring a combination of low ESS, large plaque burden and large necrotic core (53\% vs. $9 \%$ in lumen narrowings without these characteristics $)^{15}$. Plaque fissuring or frank plaque rupture may occur more frequently in the vulnerable atherosclerotic lesions of the LM/pLAD, while platelet activation and thrombus formation/growth resulting from plaque disruption may be enhanced in locations with low pulsatile $\mathrm{SS}^{16}$. In the PROSPECT trial, which prospectively captured the clinical course of patients presenting with an acute coronary syndrome, proximal coronary location was a predictor of plaque rupture among fibroatheromas ${ }^{12}$.
The high susceptibility of the LM/pLAD coronary region to vulnerable plaque development, platelet activation/aggregation and thrombosis may explain the relative benefit from prolonged antiplatelet therapy in this setting. The hypothesis-generating results of the study by Costa et $\mathrm{al}^{5}$ along with previous ones support the idea that prolonged therapy may keep "silent" any events which could cause full-blown thrombosis ${ }^{2}$. This protective effect may be especially evident in the region of the proximal left coronary artery which is more frequently exposed to low local SS. Local factors contributing to the development of high-risk coronary regions may thus be another item on the list of risk factors that could help us determine the trade-off between ischaemic and bleeding risk, and make a well-informed tailored decision on the optimal duration of DAPT for an individual patient (Figure 1).

\begin{tabular}{|lc|}
\hline PATIENT CHARACTERISTICS & LOCAL FACTORS? \\
> Acute coronary syndrome (at presentation) & Low shear stress \\
> Male gender & , Proximal location \\
> Diabetes mellitus & , Thin-cap atheroma \\
> Cigarette smoking & - Large plaque burden \\
> Left ventricular dysfunction & - Positive remodelling \\
> Prior ischaemic event (myocardial & - Augmented inflammation \\
infarction, stroke) & \\
> Prior percutaneous coronary intervention & \\
\hline
\end{tabular}

Figure 1. Systemic ischaemic risk (atherothrombosis). Individual systemic ischaemic risk (atherothrombosis) for determining the optimal duration of dual antiplatelet therapy (DAPT) could be assessed according to global patient characteristics. Local factors could potentially help in tailoring the decision on DAPT duration. Low haemodynamic shear stress (SS) is causally related with the development of positively remodelled inflamed atherosclerotic plaques (thin-cap atheromas). Proximal coronary locations, in particular the left main artery/ bifurcation and proximal left anterior descending artery, are exposed to low shear stress; assessment of SS throughout the coronary vasculature could help in identifying additional high-risk coronary regions.

Hopefully, future studies will provide more evidence for identifying the optimal risk prediction toolset.

\section{Conflict of interest statement}

The authors have no conflicts of interest to declare.

\section{References}

1. Windecker S, Kolh P, Alfonso F, Collet JP, Cremer J, Falk V, Filippatos G, Hamm C, Head SJ, Jüni P, Kappetein AP, Kastrati A, Knuuti J, Landmesser U, Laufer G, Neumann FJ, Richter DJ, Schauerte P, Sousa Uva M, Stefanini GG, Taggart DP, Torracca L, Valgimigli M, Wijns W, Witkowski A. 2014 ESC/EACTS guidelines on myocardial revascularization. EuroIntervention. 2015; 10:1024-94.

2. Mauri L, Kereiakes DJ, Yeh RW, Driscoll-Shempp P, Cutlip DE, Steg PG, Normand SL, Braunwald E, Wiviott SD, 
Cohen DJ, Holmes DR Jr, Krucoff MW, Hermiller J, Dauerman HL, Simon DI, Kandzari DE, Garratt KN, Lee DP, Pow TK, Ver Lee P, Rinaldi MJ, Massaro JM; DAPT Study Investigators. Twelve or 30 months of dual antiplatelet therapy after drug-eluting stents. N Engl J Med. 2014;371:2155-66.

3. Bonaca MP, Bhatt DL, Steg PG, Budaj A, Bansilal S, Storey RF, Im K, Magnani G, Ophuis TO, Ruda M, Hamm C, Spinar J, Kiss RG, Diaz R, Van de Werf FJ, Montalescot G, Jensen EC, Held P, Braunwald E, Sabatine MC. TCT-78 Efficacy of Long-Term Ticagrelor in Stented Patients in PEGASUS-TIMI 54 [abstract]. J Am Coll Cardiol. 2015;66:doi:10.1016/j.jacc. 2015.08.121.

4. Yeh RW. Individualizing Treatment Duration of Dual Antiplatelet Therapy after Percutaneous Coronary Intervention: An Analysis from the DAPT Study. Presented at: American Heart Association Scientific Sessions; November 10, 2015; Orlando, FL. 2015.

5. Costa F, Adamo M, Ariotti S, Ferrante G, Navarese EP, Leonardi S, Garcia-Garcia H, Vranckx P, Valgimigli M. Left main or proximal left anterior descending coronary artery disease location identifies high-risk patients deriving potentially greater benefit from prolonged dual antiplatelet therapy duration. EuroIntervention. 2016;11:1222-30.

6. Papafaklis MI, Takahashi S, Antoniadis AP, Coskun AU, Tsuda M, Mizuno S, Andreou I, Nakamura S, Makita Y, Hirohata A, Saito S, Feldman CL, Stone PH. Effect of the local hemodynamic environment on the de novo development and progression of eccentric coronary atherosclerosis in humans: insights fromPREDICTION. Atherosclerosis. 2015;240:205-11.

7. Davies PF. Hemodynamic shear stress and the endothelium in cardiovascular pathophysiology. Nat Clin Pract Cardiovasc Med. 2009;6:16-26.

8. Vergallo R, Papafaklis MI, Yonetsu T, Bourantas CV, Andreou I, Wang Z, Fujimoto JG, McNulty I, Lee H, Biasucci LM, Crea F, Feldman CL, Michalis LK, Stone PH, Jang IK. Endothelial shear stress and coronary plaque characteristics in humans: combined frequency-domain optical coherence tomography and computational fluid dynamics study. Circ Cardiovasc Imaging. 2014;7:905-11.
9. Soulis JV, Farmakis TM, Giannoglou GD, Louridas GE. Wall shear stress in normal left coronary artery tree. $J$ Biomech. 2006;39:742-9.

10. Hong MK, Mintz GS, Lee CW, Lee JW, Park JH, Park DW, Lee SW, Kim YH, Cheong SS, Kim JJ, Park SW, Park SJ. A threevessel virtual histology intravascular ultrasound analysis of frequency and distribution of thin-cap fibroatheromas in patients with acute coronary syndrome or stable angina pectoris. Am J Cardiol. 2008;101:568-72.

11. Wykrzykowska JJ, Mintz GS, Garcia-Garcia HM, Maehara A, Fahy M, Xu K, Inguez A, Fajadet J, Lansky A, Templin B, Zhang Z, de Bruyne B, Weisz G, Serruys PW, Stone GW. Longitudinal distribution of plaque burden and necrotic core-rich plaques in nonculprit lesions of patients presenting with acute coronary syndromes. JACC Cardiovasc Imaging. 2012;5:S10-8.

12. Zheng B, Mintz GS, McPherson JA, De Bruyne B, Farhat NZ, Marso SP, Serruys PW, Stone GW, Maehara A. Predictors of Plaque Rupture Within Nonculprit Fibroatheromas in Patients With Acute Coronary Syndromes: The PROSPECT Study. JACC Cardiovasc Imaging. 2015;8:1180-7.

13. Phinikaridou A, Hua N, Pham T, Hamilton JA. Regions of low endothelial shear stress colocalize with positive vascular remodeling and atherosclerotic plaque disruption: an in vivo magnetic resonance imaging study. Circ Cardiovasc Imaging. 2013;6:302-10.

14. Seneviratne A, Hulsmans M, Holvoet P, Monaco C. Biomechanical factors and macrophages in plaque stability. Cardiovasc Res. 2013;99:284-93.

15. Papafaklis MI, Mizuno S, Takahashi S, Coskun AU, AntoniadisAP, TsudaM, FeldmanCL, Saito S, StonePH.Incremental predictive value of combined endothelial shear stress, plaque necrotic core, and plaque burden for future cardiac events: A post-hoc analysis of the PREDICTION study. Int $J$ Cardiol. 2016;202:64-6.

16. Yin W, Shanmugavelayudam SK, Rubenstein DA. The effect of physiologically relevant dynamic shear stress on platelet and endothelial cell activation. Thromb Res. 2011;127:235-41. 